\title{
Audit Pengelolaan Sekolah Menggunakan Process Mining
}

\author{
Kurnia Siwi Kinasih ${ }^{1, *}$, Dyah Ayu Wiranti², Ahmad Fayyadh Qaimul Haq ${ }^{3}$, Muhammad Ainul \\ Yaqin $^{4}$, Abd. Charis Fauzan ${ }^{5}$ \\ 1,2,3,4 Jurusan Teknik Informatika, Universitas Islam Negeri Maulana Malik Ibrahim, Indonesia \\ ${ }^{5}$ Program Studi Ilmu Komputer, Universitas Nahdlatul Ulama Blitar, Indonesia \\ 117650072@student.uin-malang.ac.id; ${ }^{2} 17650093 @$ student.uin-malang.ac.id; ${ }^{3} 17650091 @$ student.uin-malang.ac.id; \\ 4yaqinov@ti.uin-malang.ac.id; ${ }^{5}$ abdcharis@unublitar.ac.id \\ * corresponding author
}

INFO ARTIKEL

\section{Sejarah Artikel}

Diterima: 22 Desember 2019

Direvisi: 10 Mei 2020

Diterbitkan: 30 Desember 2020

\section{Kata Kunci}

Audit

Audit Pengelolaan Sekolah

Process Mining

\begin{abstract}
ABSTRAK
Tujuan dari pembuatan paper ini adalah untuk melakukan audit pengelolaan sekolah dengan menggunakan metode process mining dan memanfaatkan aplikasi RapidProM. Data yang digunakan dalam audit pengelolaan sekolah ini merupakan data primer yang diperoleh dari observasi dan dokumentasi di SMAN 1 Tanjung Jabung Timur, kemudian diproses dengan menerapkan metode process mining. Dengan adanya penelitian ini diharapkan dapat melakukan pengelolaan organisasi yang ada di sekolah, sehingga pengelolaan organisasi di sekolah akan lebih efektif. Dengan adanya audit pengelolaan sekolah, pengelolaan sekolah akan memenuhi kualitas dan standar yang sesuai dengan Standar Nasional Pendidikan. Hasil penelitian audit pengelolaan sekolah dengan metode process mining yang menggunakan empat algoritma diantaranya Algoritma Alpha miner, Algoritma Fuzzy miner, Algoritma Heuristic miner, dan Algoritma Process tree dinilai memiliki kesesuaian yang tepat terhadap data yang ada. Dari hasil penelitian audit pengelolaan sekolah ini dapat disimpulkan persentase yang didapatkan dari masing masing algoritma, yaitu pada algoritma Alpha miner hasil persentase fitness 0,95 (95\%) dan precision 0,9 (90\%), pada algoritma Heuristic miner hasil persentase fitness $0,972(97,2 \%)$ dan precision $0,83(83 \%)$, pada algoritma Process tree hasil persentase fitness 0,98 (98\%) dan precision 1 (100\%), pada algoritma Fuzzy miner hasil persentase fitness 0,99 (99\%) dan precision $0,915(91,5 \%)$.
\end{abstract}

\section{PENDAHULUAN}

Sekolah merupakan suatu organisasi pemerintah, dimana lembaga pendidikan yang ada di sekolah bersifat formal, nonformal, maupun informal. Sekolah memiliki peranan yang sangat penting untuk kemajuan generasi muda saat ini. Hal ini dapat dibuktikan karena dengan manfaat sekolah yang begitu penting untuk kemajuan generasi-generasi yang akan datang. Sekolah memiliki peran penting yaitu tempat tumbuh kembangnya anak baik secara fisik, emosional, moral agama, maupun lainnya. Dengan upaya yang cukup optimal yang telah dilakukan sehingga pertumbuhan seorang anak akan lebih terjamin dan memiliki kualitas tinggi. Sekolah dapat dinilai baik dan berkualitas dengan melihat segi pengelolaan pendidikan yang ada di dalam lingkungan sekolah. Sehingga apabila pengelolaan pendidikan yang memiliki kualitas dan standar yang sesuai dengan Standar Nasional Pendidikan, maka akan memberikan dampak positif dalam jangka panjang maupun jangka pendek. Pendidikan adalah suatu usaha untuk mewujudkan dalam membantu pertumbuhan anak agar menjadi pribadi yang mandiri, bertanggung jawab dalam melaksanakan tugasnya, serta mengembangkan kepribadiannya. Dalam mengelola lembaga pendidikan sangat diperlukan 
adanya pengelolaan sekolah yang baik juga, sehingga mampu untuk menunjang kesuksesan suatu organisasi sekolah untuk mencapai tujuannya. Oleh karena itu sangat diperlukan suatu perancangan pengelolaan sekolah [1].

Proses bisnis sekolah merupakan proses bisnis yang meliputi sekumpulan aktivitas bisnis dalam sekolah yang sudah direncanakan sebelumnya dan memiliki struktur yang saling berhubungan. Dalam penyelesaian suatu masalah yang sedang terjadi baik dengan menciptakan sebuah produk ataupun layanan dengan suatu tujuan yang ingin dicapai. Dengan hal ini makan suatu proses bisnis dapat diselesaikan dengan membagi dalam beberapa sub proses. Sub proses merupakan suatu proses yang memiliki atribut sendiri tetapi juga memiliki kontribusi dalam mencapai suatu tujuan dari sub proses itu sendiri. Pada umumnya suatu analisis proses bisnis juga berkaitan dengan proses dan subproses didalam yaitu berkaitan dengan analisis proses bisnis pada umumnya juga melibatkan sebuah pemetaan proses dan subproses mulai dari dalam sampai aktivitasnya [2].

Perancangan pengelolaan sekolah dapat dikelola dengan proses bisnis yang ada di sekolah. Proses tersebut dapat dimanfaatkan sebagai penilai tingkat kesuksesan dalam lembaga pendidikan. Suatu lembaga pendidikan dapat dikatakan sukses dan memiliki akreditasi yang baik apabila dapat meningkatkan kualitas pendidikannya. Hal ini sangat diperlukan karena dapat menarik peminat siswa dalam memilih lembaga pendidikan yang tepat. Tuntutan pimpinan tertinggi dalam lembaga pendidikan juga harus terpenuhi, sehingga pengukuran kinerja tersebut dapat dilakukan dengan adanya proses audit. Audit sangat penting dilakukan untuk mencapai target yang diinginkan pada suatu perencanaan proses bisnis serta melakukan evaluasi terhadap segala permasalahan atau kendala yang ada. Audit sekolah merupakan struktur atau sebuah proses yang saling berkaitan, dimana hal ini dimanfaatkan untuk mengendalikan organisasi dalam mencapai tujuannya dan menyeimbangkan risiko yang mungkin terjadi. Risiko yang akan dihadapi dapat diketahui melalui adanya proses audit [3]. Manfaat audit pengelolaan sekolah yaitu untuk meningkatkan kualitas sekolah. Pelaksanaan proses bisnis di sekolah seringkali mengalami kendala. Kendala seperti ketidaksesuaian dengan harapan yang diinginkan, hal tersebut dapat diketahui dan dapat diperhitungkan dengan adanya proses audit. Dengan adanya audit yang dilakukan pada suatu sekolah akan menjadi solusi untuk mengatasi kekurangan dan kendala pada proses bisnis sekolah tersebut.

Audit internal merupakan salah satu bagian dari tata kelola perusahaan yang baik [4] [5]. Reformasi tata kelola perusahaan saat ini, semakin banyak dewan, komite audit, dan manajemen memandang fungsi tersebut sebagai aktivitas tata kelola penting yang menawarkan manfaat signifikan bagi organisasi [6]. Untuk mencapai potensi tersebut, audit internal harus menunjukkan kinerja dan efektivitas yang tinggi. Peraturan baru mengamanatkan bahwa kegiatan tata kelola yang efektif dan dapat diverifikasi mengasumsikan profil organisasi yang jauh lebih tinggi. Misalnya, jika suatu perusahaan yang kompleks diharuskan untuk mengesahkan pengendalian internalnya atas pelaporan keuangan untuk mematuhi peraturan, auditor eksternal perusahaan sebagai tanda bahwa kekurangan yang signifikan atau bahkan kelemahan dalam pengendalian internal yang ada mungkin melihat fungsi audit internal yang tidak efektif. Hal ini dapat mempengaruhi opini auditor dan merusak reputasi perusahaan terutama dalam lingkungan sekolah. Dalam melakukan pengamatan audit pengelolaan sekolah untuk meningkatkan kualitas sekolah perlu menggunakan metode process mining.

Process mining merupakan suatu metode dengan teknologi baru yang dinilai berkaitan dengan BPM [7]. Dengan adanya BPM (Business Process Management) ini bertujuan untuk mengamati perilaku proses bisnis dalam suatu organisasi sekolah, sehingga nantinya mendapatkan suatu model bisnis dalam sekolah. Process mining ini dapat mengetahui proses akademik dalam organisasi sekolah yang sedang terjadi, process mining juga dapat 
mengetahui apakah proses sudah berjalan sesuai rancangan sebelumnya. Selain itu process mining juga dinilai mampu memprediksi jumlah keterlambatan yang terjadi sehingga dengan adanya process mining juga dapat membuat rancangan model yang tepat guna dalam menyelesaikan masalah, sehingga membuat organisasi bisnis yang ada dalam lingkungan sekolah menjadi lebih baik.

Tujuan dari penelitian ini adalah untuk melakukan evaluasi terhadap proses bisnis sesuai dengan target yang diinginkan. Penulis berharap dengan adanya audit pengelolaan sekolah dengan metode process mining diharapkan mampu mengatasi dalam proses pengelolaan organisasi yang ada di sekolah sehingga akan jauh lebih efektif. Selain itu dengan adanya audit pengelolaan sekolah juga dapat menyeimbangkan resiko yang mungkin terjadi, karena dengan proses audit resiko yang akan terjadi dapat diketahui. Adapun batasan masalah dalam penelitian ini antara lain proses bisnis dilakukan pada instansi sekolah, selain itu metode yang diterapkan dalam audit pengelolaan sekolah merupakan metode process mining.

\section{METODE}

\section{Pengumpulan Data}

Dalam melakukan penelitian tentu membutuhkan suatu tahapan yang tepat mempermudah jalannya suatu penelitian yang dilakukan. Sehingga peneliti melakukan tahapan yang dimulai dari proses analisis data sampai penelitian yang akan dilakukan. Dalam melakukan penelitian audit pengelolaan sekolah, peneliti menggunakan data primer dan data sekunder. Dimana data primer diperoleh dari hasil observasi dan dokumentasi di SMAN 1 Tanjung Jabung Timur. Data tersebut nantinya akan diproses dengan menerapkan metode process mining dengan menggunakan algoritma Alpha miner, Algoritma Fuzzy miner, Algoritma Heuristic miner, dan Algoritma Process tree. Sedangkan data sekunder yang digunakan berupa data dari penulis penelitian-penelitian yang sudah ada sebelumnya serta literatur lainnya seperti internet serta laporan pendukung lainnya sebagai pelengkap informasi data primer.

\section{Event Log Audit Sekolah}

\begin{tabular}{|c|c|c|c|c|c|c|c|}
\hline T:conce... $\uparrow$ & T:creator & E:Activity & E:Gedung & E:Resource & E:concept:n... & E:org:resour... & E:time:times... \\
\hline 1 & Fluxicon Nitro & Pendaftaran Siswa Baru & A & User 1 & Pendaftaran ... & User 1 & Jun $30,2020 \ldots$ \\
\hline 1 & Fluxicon Nitro & Periksa Kelengkapan Data Kedua & A & User 2 & Periksa Kele... & User 2 & Jul 1, 20204 .... \\
\hline 1 & Fluxicon Nitro & Ujian & A & User 3 & Ujian & User 3 & Jul 5, 20209 :.... \\
\hline 1 & Fluxicon Nitro & Cek Nilai Ujian & A & User 4 & Cek Nilai Ujian & User 4 & Jul $6,20205 \ldots$ \\
\hline 1 & Fluxicon Nitro & Pendaftaram Ulag & A & User 1 & Pendaftaram ... & User 1 & Jul 7, 20208 .... \\
\hline 2 & Fluxicon Nitro & Pendaftaran Siswa Baru & A & User 3 & Pendaftaran ... & User 3 & Jun $30,2020 \ldots$ \\
\hline 2 & Fluxicon Nitro & Ujian & A & User 3 & Ujian & User 3 & Jun $30,2020 \ldots$ \\
\hline 2 & Fluxicon Nitro & Periksa Kelengkapan Data Pertama & A & User 5 & Periksa Kele... & User 5 & Jun $30,2020 \ldots$ \\
\hline 2 & Fluxicon Nitro & Cek Nilai Ujian & A & User 4 & Cek Nilai Ujian & User 4 & Jul $5,20205 \ldots$ \\
\hline 2 & Fluxicon Nitro & Lulus & A & User 6 & Lulus & User 6 & Jul $8,20206 \ldots$ \\
\hline 3 & Fluxicon Nitro & Pendaftaran Siswa Baru & A & User 1 & Pendaftaran ... & User 1 & Jun $30,2020 \ldots$ \\
\hline 3 & Fluxicon Nitro & Periksa Kelengkapan Data Pertama & A & User 3 & Periksa Kele... & User 3 & Jun $30,2020 \ldots$ \\
\hline 3 & Fluxicon Nitro & Ujian & A & User 6 & Ujian & User 6 & Jun $30,2020 \ldots$ \\
\hline 3 & Fluxicon Nitro & Cek Nilai Ujian & A & User 4 & Cek Nilai Ujian & User 4 & Jul 6, $20203: \ldots$ \\
\hline 3 & Fluxicon Nitro & Tidak Lulus & A & User 4 & Tidak Lulus & User 4 & Jul $6,20206 \ldots$ \\
\hline
\end{tabular}

Gambar 1. Event Log Audit Sekolah

Dalam proses bisnis audit pengelolaan sekolah salah satu tahapannya yaitu dengan membuat event log. Event log tersebut digunakan sebagai proses pendataan histori yang berupa audit trail dalam suatu tool sistem informasi. Event log yang digunakan dalam audit 
pengelolaan sekolah ini dengan menggunakan akademik sekolah yang dibuat menjadi 6 case dan pada masing-masing case mempunyai 5 event, 5 event, 8 event, 5 event, 10 event, dan 5 event seperti gambar diatas.

\section{ProM Tools}

ProM Tools merupakan sebuah jembatan yang dimanfaatkan dalam penelitian ini untuk memperoleh model proses bisnis. Setelah ini dapat dilakukan evaluasi dari beberapa proses bisnis yaitu dengan cara membandingkan nilai fitness dan nilai precision. Terdapat beberapa fitur yang dimiliki ProM Tools, dimana dari fitur yang ada dapat dimanfaatkan untuk melakukan interaksi antara beberapa plugin. Implementasi dari suatu algoritma inilah yang merupakan plugin. Dalam penggunaan ProM Tools ini sangatlah kompatibel, dimana hal ini tidak diperlukan kompilasi ulang suatu kode. Dapat dilihat pada gambar dibawah untuk mengetahui gambaran framework ProM Tools [8].

\section{Ekstensi Data Event Log}

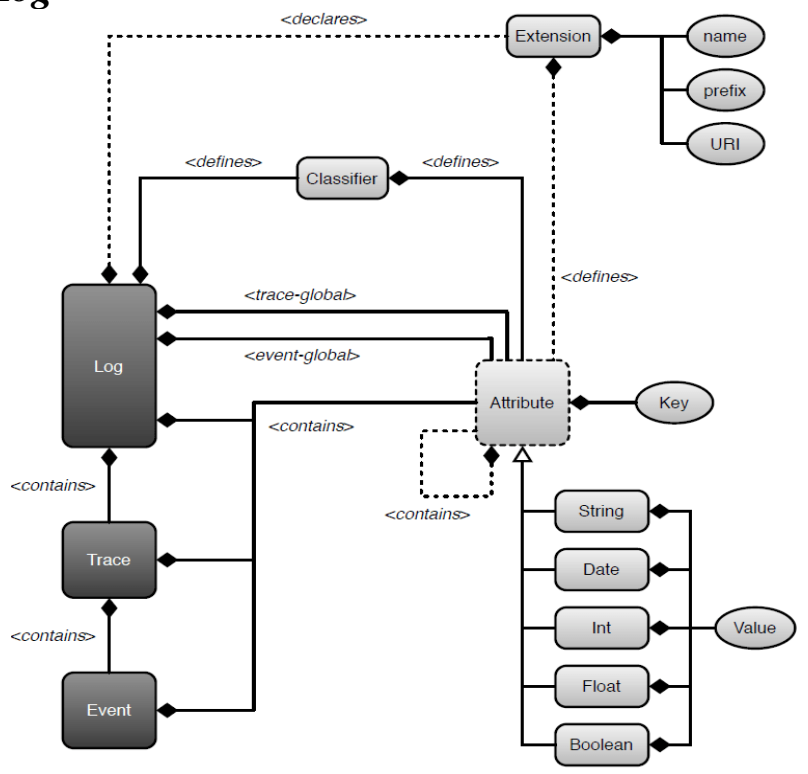

Gambar 2. XES Ekstensi Data Event Log Meta-Model

Sebagaimana Gambar 2, dalam proses discovery pada RapidProM maka sangat diperlukan suatu ekstensi data. Ekstensi data adalah sebuah proses merubah format dari .csv ke format .xes. Perpindahan format tersebut untuk melakukan proses discovery dengan menggunakan sebuah aplikasi process mining berupa RapidProM. Aplikasi yang digunakan yaitu dalam ekstensi data merupakan ProM Import atau Disco, dimana ProM Import tersebut dapat mengubah format menjadi .xes [9].

\section{HASIL DAN PEMBAHASAN}

\section{Discovery Process}

Dengan data yang telah diperoleh langkah selanjutnya yaitu dengan melakukan pemodelan yang sesuai dengan data yang telah didapatkan. Dengan menggunakan aplikasi Rapidminer pada sistem operasi windows maka pemodelan dapat dilakukan. Pemodelan yang dilakukan dengan menggunakan algoritma, yaitu algoritma Alpha miner, Algoritma Fuzzy miner, Algoritma Heuristic miner, dan Algoritma Process tree. Dari keempat algoritma tersebut dinilai memiliki kesesuaian yang tepat terhadap data yang telah diperoleh sebelumnya. Dengan pemodelan ini dapat diketahui bagaimana algoritma dari keempat metode tersebut bekerja untuk membentuk suatu proses bisnis audit pengelolaan sekolah. 
Selain itu ketepatan dalam memodelkan proses bisnis yang ada di lingkungan sekolah dengan keempat algoritma tersebut juga dapat diketahui. Dengan pemodelan pada RapidProM, kemudian dilakukan proses import data event log dengan format .xes, sebagaimana pada Gambar 3.

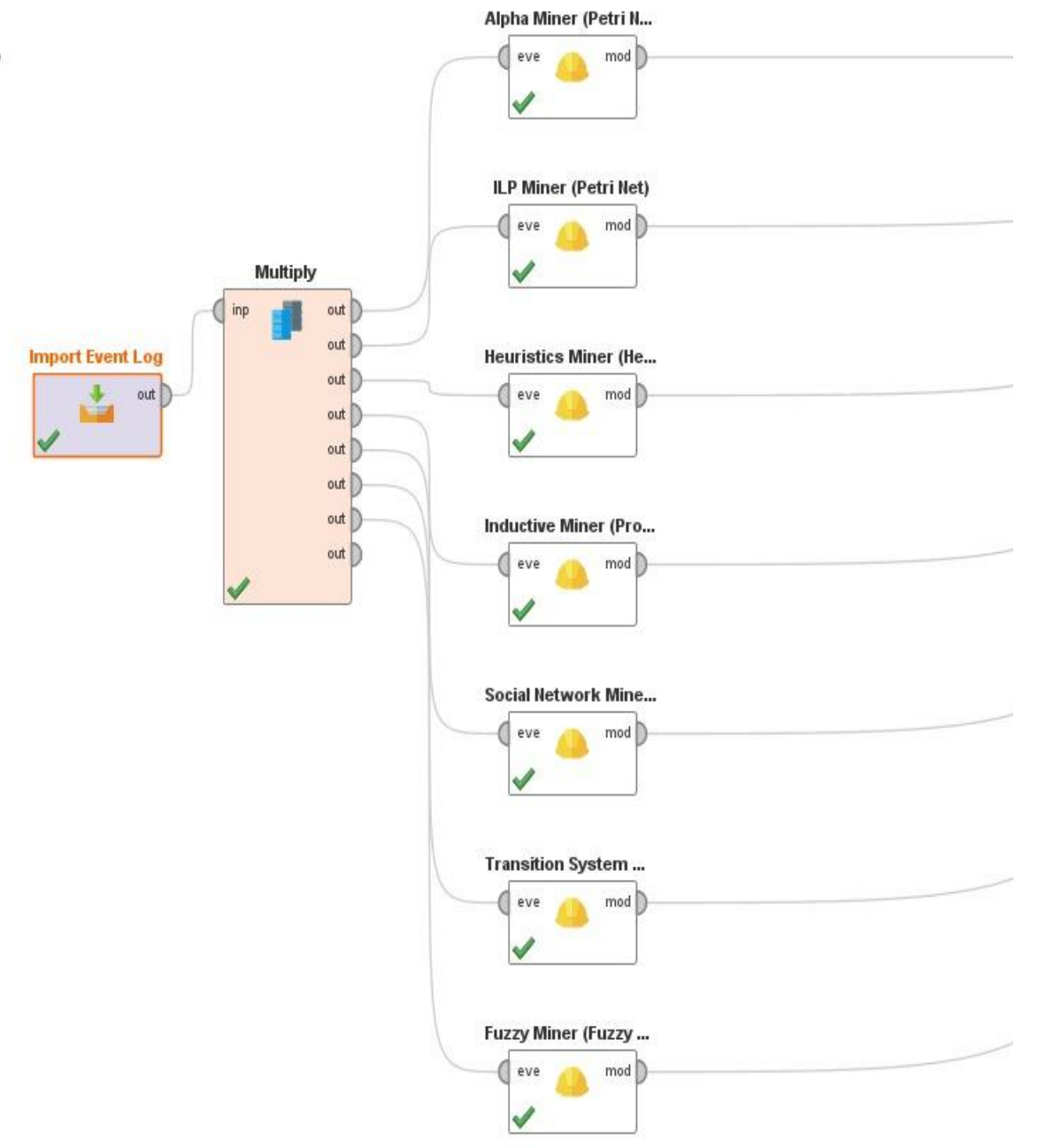

Gambar 3. Pemodelan Proses Bisnis Sekolah dengan Tools RapidProM

Dengan memasukkan data yang telah dijelaskan sebelumnya pada aplikasi, maka langkah selanjutnya dengan pembuatan pemodelan, dimana data yang tersebut dipakai dengan menggunakan 4 algoritma yang berbeda-beda.

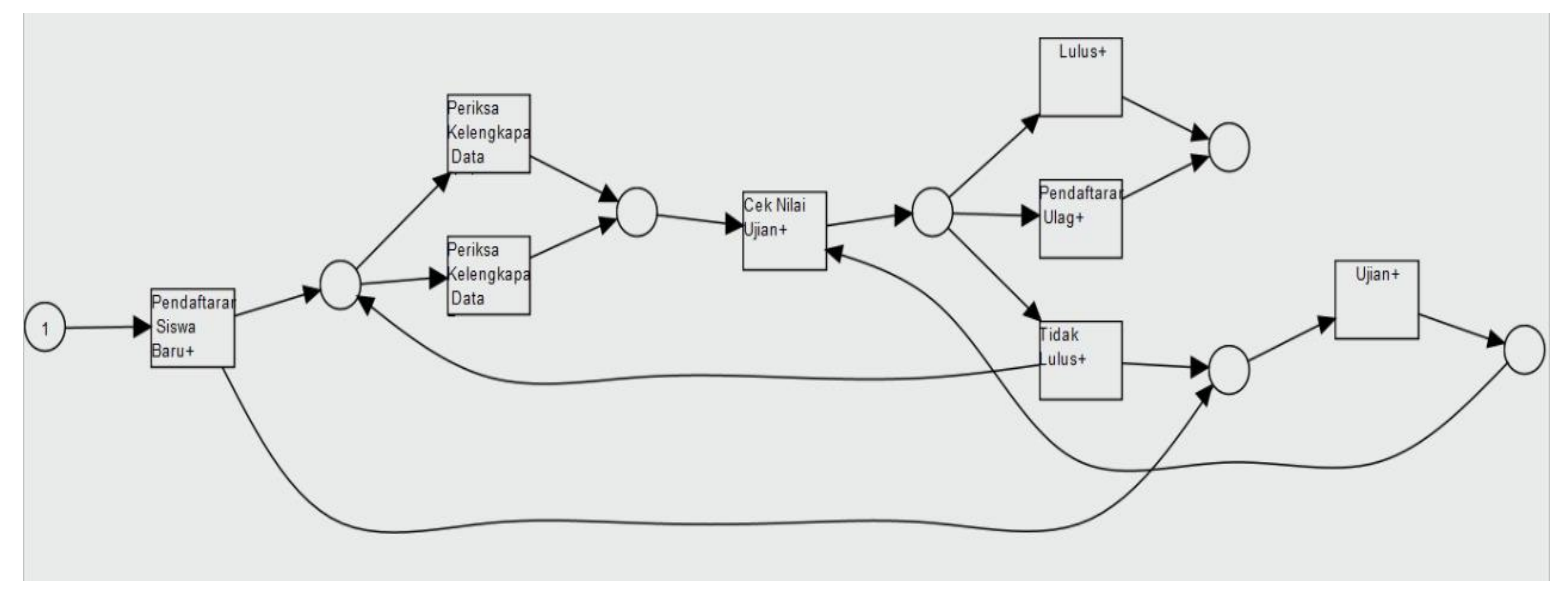


Gambar 4. Pemodelan Algoritma Alpha miner

Pemodelan pada Gambar 4 merupakan hasil dari pemodelan algoritma Alha Miner. Model ini memiliki tampilan yang menampilkan semua detail tanpa adanya pembeda untuk proses yang penting dan tidak penting atau biasanya disebut dengan spaghettilike. Proses bisnis diatas sangat kompleks dan masih tidak terstruktur dengan baik.

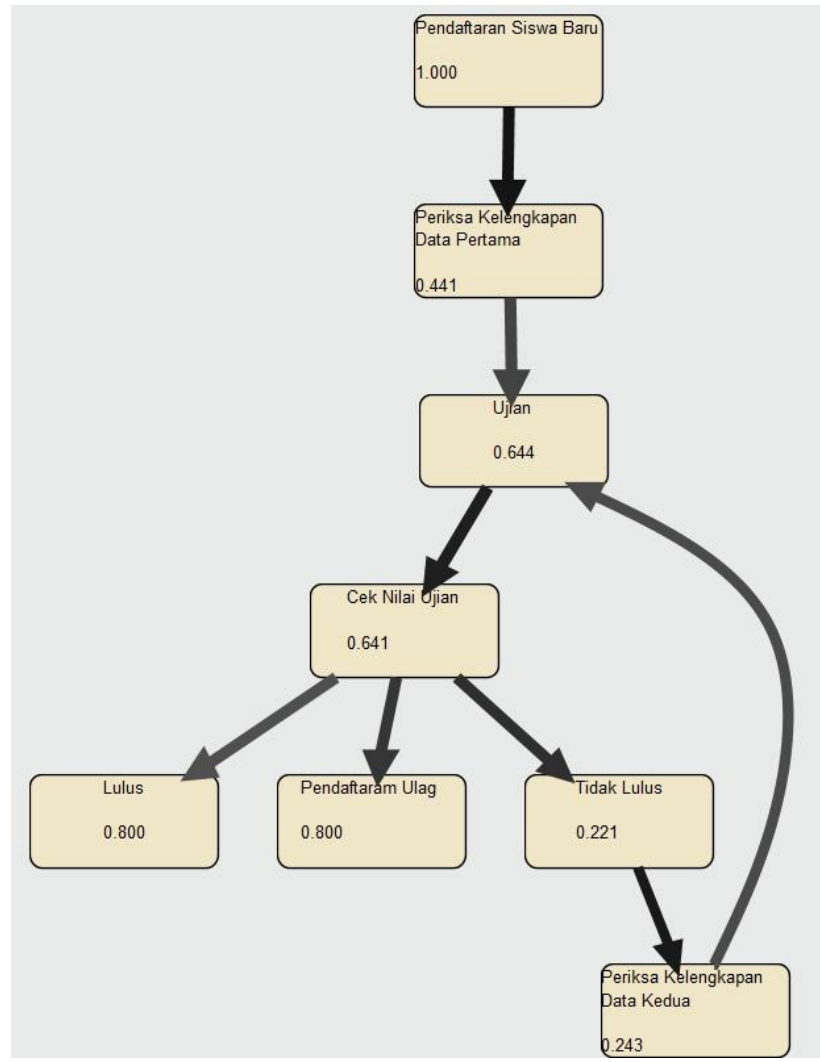

Gambar 5. Pemodelan Algoritma Fuzzy miner

Pada pemodelan fuzzy miner diatas lebih mengacu pada pemodelan real-life log. Pemodelan ini didasarkan pada fuzzy adaptive graph simplification algorithm yang digunakan untuk menyederhanakan bentuk proses bisnis tersebut mudah untuk dipahami. Dapat dilihat dari pemodelan datas yang menampilkan proses bisnis dengan sederhana namun memiliki informasi yang baik. Pada pemodelan fuzzy miner diatas jauh lebih sederhana dan mudah dimengerti dibandingkan dengan menggunakan alpha miner.

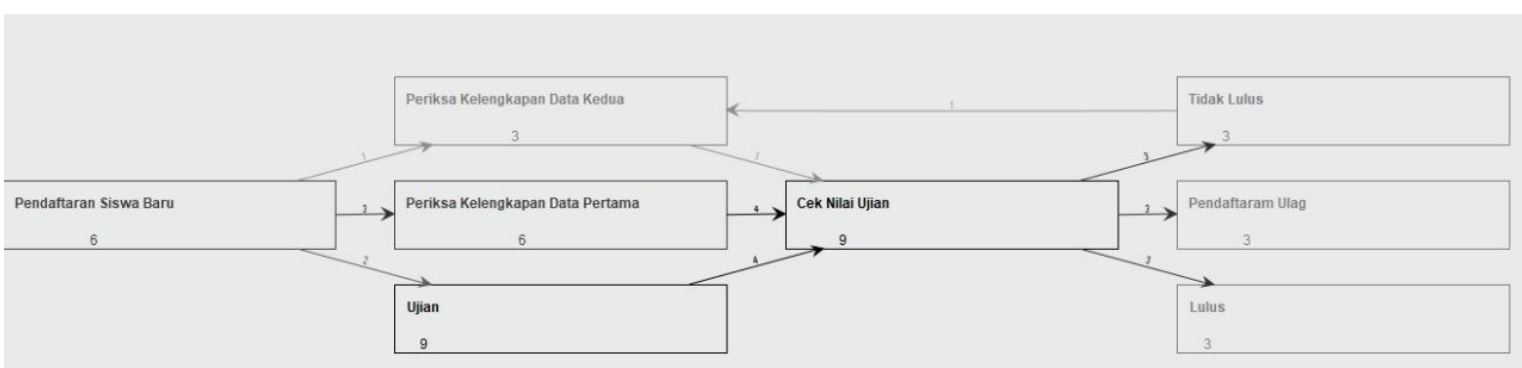

Gambar 6. Pemodelan Algoritma Heuristic miner

Pemodelan heuristic mirip dengan pemodelan alpha dimana pada pemodelan ini hasilnya juga seringkali spaghettilike. Struktur proses bisnisnya kompleks dan masih belum terstruktur dengan baikakan tetapi pada proses bisnis ini sedikit lebih sederhana dari model 
proses bisnis menggunakan metode alpha miner. Proses bisnis ini merupakan proses bisnis perbaikan dari metode alpha miner.

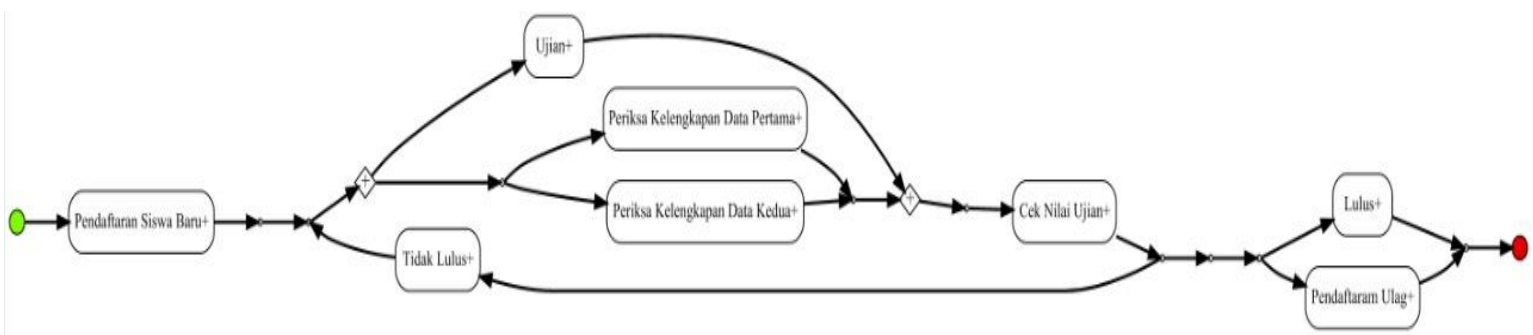

Gambar 7. Pemodelan Algoritma Inductive Miner (Process tree)

Pada proses bisnis ini hampir mirip dengan bentuk model proses menggunakan pemodelan alpha miner. Perbedaannya terdapat pada output yang dihasilkan pada model inductive miner hanya satu saja.

\section{Conformance Checking}

Conformance checking merupakan suatu proses pengecekan dalam suatu model. Dalam penelitian ini conformance checking dimanfaatkan untuk megetahui ketidaksamaan suatu model proses dan event log. Suatu event log dan petri net dapat dikatakan sesuai apabila petri net dapat menjalankan trace dalam event log. Maka dengan hal ini petri net harus menguraikan event log dalam sequence. Dalam melakukan pengukuran suatu kualitas model dari process mining conformance checking memiliki beberapa kriteria [10] yaitu :

- Fitness, fitness merupakan suatu model yang diperoleh dengan menampilkan aktivitas yang terjadi pada event log. Perhitungan nilai fitness yaitu dengan melihat apakah suatu model sesuai dengan event log. Perhitungan ini menggunakan teknik replay yaitu dengan menjabarkan perhitungan fitness, sehingga memperoleh nilai 0 apabila buruk dan 1 apabila baik atau sempurna. Persamaan 1 merupakan rumus perhitungan nilai fitness :

$$
: \frac{1}{2}\left(1-\frac{\sum_{\sigma \in L} L(\sigma) \times m_{N, \sigma}}{\sum_{\sigma \in L} L(\sigma) \times c_{N, \sigma}}\right)+\frac{1}{2}\left(1-\frac{\sum_{\sigma \in L} L(\sigma) \times r_{N, \sigma}}{\sum_{\sigma \in L} L(\sigma) \times p_{N, \sigma}}\right)_{1}
$$

Keterangan: $\quad \sum_{\sigma \in L} L(\sigma) \times m_{N, \sigma}$

Dimana $\mathrm{L}(\sigma)$ merupakan frekuensi jejak $\sigma$ dan $\mathrm{mN}, \sigma$ adalah jumlah token yang hilang untuk satu instance dari $\sigma$.

$\mathrm{P} \quad$ : token yang dihasilkan

$\mathrm{C}$ : token yang digunakan

$\mathrm{M} \quad$ : token hilang

$\mathrm{R} \quad$ : token sisa

- Precision, precision merupakan suatu model yang dimanfaatkan untuk melakukan evaluasi suatu model. Precision dapat melakukan evaluasi apabila terdapat banyak behavior yang diperbolehkan dalam suatu model, tetapi dalam event log. sebenarnya tidak pernah ada. Dalam melalukan perhitungan precision dapat dilakukan dengan menggunakan Persamaan 2.

$$
a_{B}^{l}=\frac{\left|S_{F}^{l} \cap S_{F}^{m}\right|}{2 *\left|S_{F}^{m}\right|}+\frac{\left|S_{P}^{l} \cap S_{P}^{m}\right|}{2 *\left|S_{P}^{m}\right|}
$$


Keterangan:

$S_{F}^{l}$ :jumlah relasi event $\log$

$S_{F}^{m}$ : jumlah relasi pada model

$S_{P}^{l}$ : jumlah relasi precedes pada event $\log$

$S_{P}^{m}$ : jumlah relasi precedes pada model

- Generalization, generalization merupakan suatu model yang diperoleh dengan mengeneralisasi perilaku dalam event log.

- Simplicity, simplicity merupakan model yang paling sederhana, dimana model sederhana inilah yang mudah untuk dipahami.

Langkah dalam melalukan conformance checking yaitu dengan menguji nilai fitness dan precision yang telah dihasilakan oleh proses discovery. Tabel di bawah merupakan hasil pengujian dari empat metode yaitu algoritma Alpha miner, Algoritma Fuzzy miner, Algoritma Heuristic miner, dan Algoritma Process tree.

Tabel 1. Hasil Pengujian Conformance Checking

\begin{tabular}{|c|c|c|c|c|c|c|c|}
\hline \multicolumn{2}{|c|}{ Alpha miner } & \multicolumn{2}{|c|}{ Heuristic miner } & \multicolumn{2}{c|}{$\begin{array}{c}\text { Inductive Miner } \\
\text { (Process tree) }\end{array}$} & \multicolumn{2}{c|}{ Fuzzy miner } \\
\hline $\mathrm{F}$ & $\mathrm{P}$ & $\mathrm{F}$ & $\mathrm{P}$ & $\mathrm{F}$ & $\mathrm{P}$ & $\mathrm{F}$ & $\mathrm{P}$ \\
\hline 0,95 & 0,9 & 0,972 & 0.83 & 0,98 & 1 & 0.99 & 0,915 \\
\hline
\end{tabular}

Setelah melakukan percobaan dengan melakukan process mining didapatkan hasil jika pemilihan keempat algoritma antara Algoritma Alpha miner, Algoritma Fuzzy miner, Algoritma Heuristic miner, dan Algoritma Process tree dinilai memiliki kesesuaian yang tepat terhadap data yang telah diperoleh. Persentase dari masing algoritma dengan menghitung nilai fitness dan precision yaitu: Algoritma Alpha miner hasil persentase fitness 0,95 (95\%) dan precision 0,9 (90\%), pada algoritma Heuristic miner hasil persentase fitness 0,972 (97,2\%) dan precision 0,83 (83\%), pada algoritma Process tree hasil persentase fitness $0,98(98 \%)$ dan precision 1 (100\%), pada algoritma Fuzzy miner hasil persentase fitness $0,99(99 \%)$ dan precision $0,915(91,5 \%)$.

Audit lingkungan sekolah dilaksanakan sebagai proses belajar mengajar yang aktif dan partisipatif, yang tujuannya adalah untuk memberikan diagnosis lingkungan sekolah. Untuk tujuan ini, seluruh komunitas pengajar harus berpartisipasi dalam mengambil komitmen, menyusun rencana aksi untuk beberapa topik tertentu, dan mengevaluasi proses dan hasil. Proses pendidikan ini adalah kunci penting [11]. Kita perlu mengetahui apa yang benarbenar dimasukkan ke dalam kurikulum dan bagaimana hal itu dikerjakan untuk memahami bagaimana pengalaman ini berkontribusi untuk mencapai tujuan pendidikan untuk pembangunan berkelanjutan di sekolah. Kesadaran guru tentang tujuan dan partisipasi aktif sangat penting untuk seluruh proses integrasi kurikuler. Untuk itu, pendidikan guru harus sesuai dengan model sains, teknologi, dan masyarakat baik pra maupun dalam masa jabatan [12]. Persoalan penting lainnya adalah gagasan untuk mengembangkan kriteria mutu pendidikan guru agar guru memperoleh kompetensi dalam pendidikan.

Audit internal yang efektif menilai bahwa suatu praktik audit merupakan sebuah kunci keberhasilan dan kesuksesan mereka. Untuk menyeimbangkan perubahan dalam tingkat sekolah dan untuk mencapai harapan dari kepentingan sekolah, audit internal bertugas untuk mencapai kesuksesan. Biasanya, grup audit internal dengan kinerja terbaik menunjukkan 
komitmen yang kuat pada bidang-bidang seperti sumber daya, manajemen pengetahuan, mitigasi risiko, penilaian risiko, dan teknologi.

\section{KESIMPULAN}

Dengan adanya audit internal ini dapat menunjukkan tingkat efektivitas dan pengukuran kinerja sistem yang ada. Dengan memutar kembali kebutuhan para pemegang kepentingan utamanya dan mencari tahu secara lebih dalam mengenai kinerjanya terhadap harapan kepala sekolah, guru, dan orang yang berkontribusi dalam sekolah. Sehingga fungsi adanya audit internal dalam memuaskan pengawasan dengan meningkat dan lebih menuntut harapan. Dengan menerapkan beberapa algoritma diatas dapat digunakan sebagai acuan dalam membentuk audit pengelolaan sekolah yang ada di lingkungan sekolah. Dari penelitian proses bisnis audit pengelolaan sekolah didapatkan hasil persentase dari masing masing algoritma yaitu pada algoritma Alpha miner hasil persentase fitness 0,95 (95\%) dan precision 0,9 (90\%), pada algoritma Heuristic miner hasil persentase fitness $0,972(97,2 \%)$ dan precision 0,83 (83\%), pada algoritma Process tree hasil persentase fitness 0,98 (98\%) dan precision 1 (100\%), pada algoritma Fuzzy miner hasil persentase fitness 0,99 (99\%) dan precision $0,915(91,5 \%)$.

\section{REFERENSI}

[1] V. Y. Rahmawati, M. N. Aslam, H. K. Mz, and M. A. Yaqin, "Analisis dan Perancangan Software Simulasi Pertumbuhan Kebutuhan Proses Bisnis Pondok Pesantren Berdasarkan National Minimum Standards For Boarding School,” Ilk. J. Comput. Sci. Appl. Informatics, vol. 2, no. 2, pp. 156-171, 2020.

[2] A. Yunus, A. C. Fauzan, A. N. Faizin, and K. Sabbihatul, "Analisis Control Flow Complexity Untuk Komparasi Kompleksitas Proses Bisnis Penerimaan Mahasiswa Baru Universitas Nahdlatul Ulama Blitar Berbasis Petri Net Modelling Language," Ilk. J. Comput. Sci. Appl. Informatics, vol. 1, no. 2, pp. 39-46, 2019.

[3] A. C. Fauzan, R. Sarno, and M. A. Yaqin, "Performance measurement based on coloured petri net simulation of scalable business processes," Int. Conf. Electr. Eng. Comput. Sci. Informatics, vol. 4, no. September, pp. 261-266, 2017, doi: 10.11591/eecsi.4.1045.

[4] W. G. Bowen, The board book: An insider's guide for directors and trustees. WW Norton \& Company, 2008.

[5] C. A. Mallin, HANDBOOK ON INTERNATIONAL CORPORATE GOVERNANCE. Northampton Massachusetts 01060 USA: Edward Elgar Publishing Limited, 2011.

[6] S. Curtis, C. Thomas W, and L. Scott A, "A comparison of TRMM to other basin-scale estimates of rainfall during the 1999 Hurricane Floyd flood.," Nat. Hazards, 2007.

[7] W. Van Der Aalst, "Using process mining to bridge the gap between BI and BPM," Computer (Long. Beach. Calif)., vol. 44, no. 12, pp. 77-80, 2011, doi: 10.1109/MC.2011.384.

[8] B. F. Van Dongen, A. K. A. De Medeiros, H. M. W. Verbeek, A. J. M. M. Weijters, and W. M. P. Van Der Aalst, "The ProM framework: A new era in process mining tool support," Lect. Notes Comput. Sci., vol. 3536, pp. 444-454, 2005, doi: 10.1007/11494744_25.

[9] B. F. van Dongen and S. Shabani, "Relational XES: Data Management for Process Mining," CAiSE Forum, 2015.

[10] W. Van Der Aalst et al., "Process mining manifesto," Lect. Notes Bus. Inf. Process., vol. 99 LNBIP, no. PART 1, pp. 169-194, 2012, doi: 10.1007/978-3-642-28108-2_19.

[11] M. del C. Conde and J. Samuel Sánchez, "The school curriculum and environmental education: A school environmental audit experience," Int. J. Environ. Sci. Educ., vol. 5, no. 4, pp. 477-494, 2010.

[12] B. Raj Acharya, "Factors Affecting Difficulties in Learning Mathematics by Mathematics Learners," Int. J. Elem. Educ., vol. 6, no. 2, p. 8, 2017, doi: 10.11648/j.ijeedu.20170602.11. 